\title{
DENTAL MANAGEMENT AND BLEEDING COMPLICATIONS OF PATIENTS ON LONG-TERM ORAL ANTIPLATELET THERAPY. REVIEW OF EXISTING STUDIES AND GUIDELINES
}

\author{
Atanaska Dinkova ${ }^{1}$, Donka Kirova ${ }^{1}$, Delyan Delev ${ }^{2}$ \\ 1) Department of Oral surgery, Faculty of Dental Medicine, \\ 2) Department of Pharmacology and Clinical pharmacology, \\ Medical University - Plovdiv, Bulgaria
}

\section{SUMMARY:}

Antiplatelet drugs are currently widely used in primary and especially secondary prevention of cardiovascular events.

Dental management of patients on antiplatelet therapy is still not clearly defined: the discontinuation of antiplatelet therapy increases the risk of thrombotic complications, whereas uninterrupted antiplatelet therapy is assumed to increase the bleeding complications after dental surgical procedures.

The aim of this article is to review the main antiplatelet drugs used for long-term oral antiplatelet therapy, the laboratory methods for evaluating effectiveness of this therapy, to identify the studies and guidelines available for dental management of patients on antiplatelet drugs and to summarize their conclusions and recommendations.

The methodology used through the research for the literature review includes the following sources: Medscape, Pubmed-Medline database, Science Direct, and EBSCO host, the data base of Medical University Plovdiv and specialised published books in general medicine and dentistry.
The research proceeded by searching the next

Key words: hemostasis alteration, blood coagulation disorders, antiplatelet drugs, aspirin, clopidogrel, new antiplatelet agents, dental management antiplatelet, oral surgery antiplatelet, thrombosis, fibrin sealants, tranexamic acid.

\section{INTRODUCTION:}

Antiplatelet therapy is wildly used in prevention of risk of myocardial infarction, patients with atherosclerotic vascular disease at high risk, treatment of acute coronary syndrome, prior percutaneous coronary intervention, coronary bypass, atrial fibrillation, stroke, in and treatment of arterial and venous thrombosis.

Of concern to dental practitioners is the risk of excessive bleeding during or after invasive dental procedures. Although there have been strong warnings from some authors and organizations that the risks from altering dosage of or stopping antiplatelet drugs far outweigh any benefit there remains a prevailing practice of discontinuation of thetherapy before invasive dental procedures.

Antiplatelet medicines are shown in Table 1.

Table 1. Antiplatelet agents

\begin{tabular}{|l|l|l|l|l|l|}
\hline $\begin{array}{l}\text { COX } \\
\text { Inchibitors }\end{array}$ & $\begin{array}{l}\text { Inhibitors of } \\
\text { ADP - mediated } \\
\text { activation of the } \\
\text { GPIIb/IIIa }\end{array}$ & $\begin{array}{l}\text { Prostaglandin } \\
\text { analogues }\end{array}$ & $\begin{array}{l}\text { Phosphodiester- } \\
\text { ase inhibitors }\end{array}$ & $\begin{array}{l}\text { Fibrinogen } \\
\text { receptor } \\
\text { antagonists } \\
\text { (disynergists) }\end{array}$ & $\begin{array}{l}\text { New class } \\
\text { P2Y12 } \\
\text { inhibitor }\end{array}$ \\
\hline $\begin{array}{l}\text { Acetylsalicylic } \\
\text { acid }\end{array}$ & Clopidigrel & Alprostadil & Dipyridamole & Abciximab & Prasugrel \\
\hline Indobufen & Ticlopidine & $\begin{array}{l}\text { Iloprost } \\
\text { tromethamol }\end{array}$ & & Eptifibatide & \\
\hline & Ticagrelor & & & Tirofiban & \\
\hline
\end{tabular}


Antiplatelet medicines used for long-term oral therapy are:

\section{COX Inchibitors}

Acetylsalicylic acid

In 1899, a French chemist, Charles Frederic Gerhardt was the first to isolate and prepare aspirin. The name aspirin was derived from A "Acetyl" and Spirin from "Spirsaure", an old German name for salicylic acid.

Aspirin has antiplatelet activity through its inhibition of platelet aggregation.

Platelet function and the COX-1 enzyme are irreversibly inhibited by aspirin lasting for up to 10 days (i.e., the entire life of the platelet).

Aspirin is an approximately 150 - to 200 -fold more potent inhibitor of the constitutive enzyme COX-1, which is highly sensitive to low doses of aspirin (40-80 mg daily), than COX-2. The antithrombotic properties of aspirin are effective up to $320 \mathrm{mg}$ daily. Accordingly, aspirin is maximally effective as an antithrombotic agent at doses much lower than those required for anti-inflammatory and analgesic functions. In contrast, COX-2 is inhibited only by doses high enough to have analgesic or anti-inflammatory effects.

Thus, low-dose aspirin (40 to $320 \mathrm{mg}$ ) inhibits platelet aggregation, but does not interfere with PGI2 function or its vasodilating effects. Indications: Unstable angina pectoris; Acute myocardial infarction; Prevention of a repeat myocardial infarction after an initial myocardial infarction (reinfarction prophylaxis); Following surgery or other interventions in arterial blood vessels (e.g after an aortocoronary venous bypass (ACVB), in percutaneous transluminal cor-onary angioplasty (PTCA); Prevention of transient alchemic attacks (TIA and cerebral infraction following manifestation of the precursor stages (e.g transient signs of paralysis in the face or arm muscles or transient loss of vision) [1]

Indobufen

Indobufen inhibits platelet aggregation by reversibly inhibiting the platelet cyclooxygenase enzyme thereby suppressing thromboxane synthesis.

Oral indobufen is used in the secondary prevention of thromboembolic complications in patients with or without atrial fibrillation, in the prevention of graft occlusion after coronary artery bypass graft $(\mathrm{CABG})$ surgery and in the treatment of intermittent claudication.

Indobufen may be an effective alternative for at risk patients with nonrheumatic atrial fibrillation in whom anticoagulant therapy is contraindicated or who are at higher risk of bleeding.

\section{GPIIb/IIIa}

Inhibitors of ADP-mediated activation of the

Clopidigrel

Clopidogrel is an antiplatelet agent belonging to the thienopyridine family.
Clopidogrel blocks the $\mathrm{P} 2 \mathrm{Y} 12$ receptor on the platelet cell membranes, inhibiting the ADP-induced platelet aggregation. It is a pro-drug and needs to be metabolized to its active metabolite by several hepatic cytochrome P450 isoenzymes.

Clopidogrel is indicated: as monotherapy for the prevention of atherothrombotic events in patients suffering myocardial infarction, ischaemic stroke or peripheral arterial disease and in conjunction with aspirin in patients suffering from acute coronary syndrome (ACS) for non-ST segment elevation ACS (unstable angina or non-Q-wave myocardial infarction) including patients undergoing a stent placement following percutaneous coronary intervention (PCI) and ST segment elevation acute myocardial infarction in medically treated patients eligible for thrombolytic therapy.

Platelet inhibition by clopidogrel is both dose- and time- dependent and patients are usually given a loading dose of 300-600 $\mathrm{mg}$ and then maintained on $75 \mathrm{mg} /$ day.

The duration of clopidogrel therapy varies according to the indication:

- myocardial infarction - from a few days to less than 35 days,

- ischaemic stroke - from 7 days to less than 6 months,

- following the insertion of a bare metal stent (BMS) - 4 to 12 weeks,

- following the insertion of a drug-eluting stent (DES) - 6 to 12 months (local policies vary). [2, 3, 4]

\section{Ticlopidine}

Ticlopidine is an antiplatelet drug in the thienopyridine family. Like clopidogrel, it is an adenosine diphosphate (ADP) receptor inhibitor.

Action: Inhibits platelet aggregation by altering the function of platelet membranes by blocking ADP receptors. This prevents the conformational change of glycoprotein IIb/ IIIa which allows platelet binding to fibrinogen. Ticlopidine prolongs bleeding time.

It is used in patients in whom aspirin is not tolerated, or in whom dual antiplatelet therapy is desirable.

\section{Ticagrelor}

Ticagrelor is a new direct inhibitor of the platelet $\mathrm{P}_{2} \mathrm{Y}_{12}$ receptor and therefore does not require metabolic activation. Unlike thienopyridines, ticagrelor binds reversibly to the $\mathrm{P}_{2} \mathrm{Y}_{12}$ receptor and at a site that is independent of adenosine diphosphate (ADP) but still results in suppression of ADP-induced platelet activation by temporarily "locking" the receptor in an inactive state until it dissociates. Ticagrelor has significantly faster onset and offset of antiplatelet activity compared with clopidogrel in subjects with stable coronary artery disease or acute coronary syndromes. Ticagrelor is indicated for the prevention of thrombotic events in patients with acute 
coronary syndrome or myocardial infarction with ST elevation. The drug is combined with acetylsalicylic acid unless the latter is contraindicated. [5, 7]

\section{Phosphodiesterase inhibitors}

Dipyridamole

Dipiridamole inhibits the cellular reuptake of adenosine into platelets, red blood cells and endothelial cells leading to increased extracellular concentrations of adenosine.

Dipyridamole blocks the thromboxane syntheses as well as the thromboxane receptor

In comparison with ASA which inhibits mainly platelet aggregation, dipiridamole inhibits more platelet adhesion then their aggregation.

Its action of phosphodiesterase is wholly reversible and ceases about $24 \mathrm{~h}$ after the drug is discontinued.

Used as an adjunct to oral anticoagulation for the prophylaxis of thromboembolism associated with prosthetic heart valves. Modified release dipyridamole preparations are licensed for the secondary prevention of ischaemic stroke and transient ischaemic attacks. [6]

\section{New class P2Y12 inhibitor}

Prasugrel - newest thienopyridine, which also irreversibly binds to P2Y12-receptor with a rapid onset and stronger inhibitory effect compared with clopidogrel.

Licensed for use with aspirin for the prevention of atherothrombotic events in patients with acute coronary syndrome (i.e. unstable angina, non-ST segment elevation myocardial infarction or ST segment elevation myocardial infarction undergoing primary or delayed PCI. [7, 8]

\section{Laboratory tests for evaluation the degree of the antiplatelet therapy}

Most platelet function tests have been traditionally utilized for the diagnosis and management of patients presenting with bleeding problems rather than thrombosis. However, as platelets are now implicated in the development of atherothrombosis, new and existing platelet function tests are increasingly being used for monitoring the efficacy of the antiplatelet drugs used to treat these conditions. [2]

\section{Bleeding time}

Platelet function testing began with the application of the in vivo bleeding time by Duke in 1910. The bleeding time was still regarded as the most useful screening test of platelet function until the early 1990's.

Many studies have shown that a low dose of Acetylsalicylic acid has an effect on bleeding time, but this have no clinical significance.

Literature suggests overwhelmingly that prolonged BTs do not translate into increased blood loss from surgery. [9]
The platelet aggregation (impedance) test is a more accurate screen than the cutaneous bleeding time test to determine the adequacy of platelet responsiveness to physiologic stimuli such as collagen, arachidonic acid, and adenosine diphosphate.

However the predictive power of this test and other platelet function tests for bleeding during or after invasive dental procedures is not well documented.

At present, clinical and ex vivo platelet aggregation measurements have not been particularly useful in guiding the clinician as to the risks of bleeding following dental extractions in patients who use antiplatelet drugs. $[2,10]$

Platelet count is normally between 150 and $450 \mathrm{x}$ $10^{9} / 1$ blood. A normal platelet count, however, gives no information about the platelet function.

Platelet function tests can be subdivided into platelet adherence, aggregation or activation. Light transmission aggregometry (LTA) was invented in the 1960's and soon revolutionized the diagnosis of primary haemostatic defects. LTA is still regarded as the gold standard of platelet function testing and by adding a panel of agonists to stirred platelets it is possible to obtain a large amount of information about many different aspects of platelet function.

However, it is not sufficiently sensitive to reliably detect the effect of low-dose aspirin or clopidogrel. [10]

Partial thromboplastin time (APTT) and the prothrombin time (PT) normalized using the international normalized ratio (INR) also must be interpreted with caution as they do not reflect the in vivo haemostatic response; the interaction between the vessel wall, platelets, fibrinogen and circulating coagulation factors. These tests have never been validated for the prediction of haemorrhagic tendency and are performed at $37 \mathrm{C}^{\circ}$.

Number of new tests have been used to assess the influence of antiplatelet drugs on platelets (PFA-100®, VerifyNow ${ }^{\circledR}$ Aspirin, TEG platelet mapping ${ }^{\circledR}$, Impact ${ }^{\circledR}$, and urinary Thromboxane, P2Y12 assay, TEG platelet mapping system ${ }^{\circledR}$, Impact, Plateletworks ${ }^{\circledR}$ flow cytometric analysis of activation-dependent markers), but they are still not widely available.

Formal randomized clinical trials are needed to determine the extent to which abnormalities of common laboratory tests of platelet function reflect an increased risk of bleeding at the time of invasive dental procedures. [2,10]

Therapy discontinuation and risk of adverse cardiovascular events

Stopping antiplatelet agents prior to surgical procedures may increase the risk of thromboembolic events.

A large meta-analysis involving 50,279 patients taking aspirin for secondary prevention showed that their risk of developing major cardiovascular events after aspirin withdrawal was 3 times higher than in those who continued aspirin therapy. [11] 
Use of low-dose aspirin in patients with cardiovascular disease is estimated to prevent at least 10 to 20 fatal and nonfatal vascular events per every 1000 patients taking the drug for 1 year who are at high risk (annual 4\%$8 \%$ risk) of serious vascular events. [1]

Collet et al. published 11 cases of coronary events after aspirin cessation.

In a study of 1358 patients admitted for suspected acute coronary syndrome, Collet et al. followed prospectively 930 nonusers, 355 prior users, and 73 recent withdrawers of oral antiplatelet agents to determine if prior use or recent withdrawal influences the severity of acute coronary syndrome (ACS) and the clinical outcomes of death, myocardial infarction, and bleeding.

$5 \%$ of the patients admitted with ACS had withdrawn OAA within 3 weeks before admission. OAA was found to be an independent predictor of both mortality and bleedings at 30 days. It was concluded that prior users of OAA and patients with recent interruption of OAA displayed worse clinical outcomes than nonusers.

A study by Ferrari et al. evaluated the role of aspirin withdrawal in a cohort of 1236 patients hospitalized for ACS. A total of $51(4.1 \%)$ of these patients discontinued aspirin within 1 month of the ACS. 13 cases were withdrawn from aspirin before a dental procedure. The mean delay between aspirin withdrawal and the acute coronary event was 1- 1.9 days (range 4-17 days).

Beving et al. found that rapid withdrawal of aspirin may cause abnormally high levels of blood markers reflecting an increase of thromboxane A2 which may have possible

hazardous effects in patients with cardiovascular disease. After aspirin discontinuation, the recovery of cyclooxygenase activity may occur rapidly, with a heterogeneous synthesis of thromboxane A2 by fresh platelets.

They support the hypothesis that aspirin withdrawal in coronary patients may represent a real risk for the occurrence of a new coronary event.

In the Fischer et al. study of 8688 patients who experienced first-time acute myocardial infarction, the risk of acute myocardial infarction was 1.52 times greater for subjects who stopped taking NSAIDs including aspirin from 1 to 29 days compared with nonusers.

Overall, the data supported the conclusion that among ACS patients, the discontinuance of daily aspirin use increases the risk for adverse clinical cardiovascular outcomes during the first month after drug withdrawal. Patients with stents are at high risk of thromboembolic events and it has been found that the greatest risk for stent thrombosis is premature discontinuation of clopidogrel.

It is therefore recommended that antiplatelet therapy should not be stopped at any time without discussion with an interventional cardiologist, but especially within the first
6 -12 months after DES insertion or the first 6-12 weeks after BMS insertion. [12, 13]

\section{Risks of bleeding associated with continuing antiplatelet medications in the perioperative period}

In every day practice owing to the threat of bleeding, patients taking aspirin are often asked by their dentist or surgeon to discontinue antiplatelet medications before a procedure. This "recommendation" is often made without consulting the cardiologist or the general practitioner who prescribed the antiplatelet agents.

More than 20 studies and guidelines have been investigated.

Lillis et al. reported 111 patients on clinically indicated antiplatelet therapy: aspirin $(\mathrm{n}=42)$, clopidogrel $(n=36)$, and aspirin and clopidogrel $(n=42)$. After teeth extractions they reported $66.7 \%$ occurrence of bleeding within 30 minutes for patients on dual antiplatelet therapy, $2.6 \%$ for single antiplatelet and $0.4 \%$ in control subjects, differences which were statistically significant. However, all immediate bleeding complications were successfully managed with local haemostatic measures. No patient developed any late haemorrhage. They concluded that dental extractions may be safely performed in patients receiving single or dual antiplatelet therapy when appropriate local haemostatic measures are taken, thus averting thrombotic risk of temporary antiplatelet discontinuation.

In a study of Nooh et al. 102 subjects were on ASA $81 \mathrm{mg}$ once a day for the previous 6 months. The control group of 87 subjects did not use ASA. They concluded that extraction of teeth in patients taking $81 \mathrm{mg}$ of ASA did not cause significant bleeding post-operatively. All postoperative bleeding was controlled by using good local measures.

Valerin et al. conducted a study with healthy patients who presented for a single tooth extraction. They were randomized to aspirin ( $325 \mathrm{mg} /$ day) or placebo for two days prior to extraction, and for two days following the extraction. The cutaneous bleeding time was not statistically different between the aspirin and placebo group. There was no difference in duration of bleeding following extraction between the aspirin and placebo groups, or with intraoperative or postoperative bleeding outcomes.

Cardona-Tortajada et al. monitored 155 patients on antiplatelet therapy who underwent dental extractions. 26 patients had minor bleeding complications which were controlled by local haemostasis measurements.

They concluded that there is a clear relationship between the numbers of extractions in the same session and the subsequent haemorrhage and advice not extracting more than 3 teeth at a time, and that these should either be adjacent or correlative, not in different parts of the dental arch. For molar teeth, no more than two adjacent teeth should be extracted. 
Park MW et al. examined the safety of continuation during dental extraction of dual or triple antiplatelet therapy in 100 patients with DES. They found that no severe bleeding or major cardiovascular events occurred after dental extraction except for 2 cases (2\%). These data suggest that it may be feasible for patients with DES to continue their antiplatelet therapy, even triple antiplatelet therapy, for dental extraction. Although there remains a risk for bleeding with this strategy, continuation of multiple antiplatelet therapy may be relatively safe.

Krishan B. et al. included in a study 82 patients requiring dental extractions of which 57 were on antiplatelet therapy (aspirin). No patient had any episode of prolonged or significant bleeding from the extraction sites. Local hemostasis had been satisfactorily obtained in all cases with the use of a pressure pack for 30 minutes. They also concluded that routine dental extractions can be safely performed in patients on long-term antiplatelet medication, with no interruption or alteration of their medication.

Madan G.A. et al. conducted a study with 51 patients on long-term therapy with acetylsalicylic acid $75 \mathrm{mg}$ to 100 $\mathrm{mg}$ daily. Aspirin was not stopped for a single patient. There was no postoperative bleeding in all cases. They concluded that most minor oral surgery procedures can be carried out safely without stopping long-term low-dose aspirin regimen.

Morimoto Y. et al. reported 87 cases, receiving antiplatelet drugs. Teeth were extracted without reducing the therapy, and oxidized cellulose was applied and suturing was performed for local hemostasis. They also concluded that sufficient haemostasis can be obtained in most cases of tooth extraction and appropriate local haemostatic methods can be successful when postoperative haemorrhage occurs. $[14,15$, $16,17,18,19,20,21]$

Patients taking antiplatelet medications with the following medical problems may be at higher risk of prolonged bleeding following dental procedures: liver impairment, and/or alcoholism, renal failure, thrombocytopenia, haemophilia or other disorder of haemostasis, currently receiving a course of cytotoxic medication, marrow disorders, any concurrent medication affecting haemostasis such as anticoagulants or anti-inflammatory drugs.

Prior to treating these patients consultation with medical specialist (cardiologist) is recommended. Referral to a dental hospital or hospital based dental clinic may be appropriate. [22, 23, 24, 25]

\section{Local haemostasis}

A local anaesthetic containing a vasoconstrictor should be administered by infiltration or by intraligamentary injection wherever practical. Regional nerve blocks should be avoided where possible. However, if there is no alternative, the local anaesthetic should be administered cautiously using an aspirating syringe.

The procedure should be as atraumatic as possible and any bleeding should be managed using local measures.

Sockets should be gently packed with an absorbable haemostatic dressing e.g. oxidised cellulose, collagen sponge or resorbable gelatin sponge then carefully sutured. Following closure, pressure should be applied to the socket(s) by using a gauze pad that the patient bites down on for 15 to 30 minutes.

Fibrin sealants also can be used to reduce postoperative hemorrhage in patients with a wide range of degrees of surgical trauma. They stimulate the last stages of the coagulation cascade, that is, the conversion of fibrinogen to fibrin. $[22,25,26,27,28]$

Tranexamic acid impedes the proteolytic degradation of fibrin by preventing the attachment of plasminogen and plasmin. A $4.8 \%$ solution has been proven to be very effective in reducing bleeding complications. [26]

Patients should be given clear instructions on the management of the clot in the postoperative period and advised:

- to look after the initial clot by resting while the local anaesthetic wears off and the clot fully forms (2-3 hours),

- to avoid rinsing the mouth for 24 hours,

- not to suck hard or disturb the socket with the tongue or any foreign object, the day,

- to avoid hot liquids and hard foods for the rest of

- to avoid chewing on the affected side until it is clear that a stable clot has formed. Care should then be taken to avoid dislodging the clot,

- if bleeding continues or restarts, to apply pressure over the socket using a folded clean handkerchief or gauze pad for 20 minutes.

- If bleeding does not stop, the dentist should be contacted; repacking and resuturing of the socket may be required. $[1,4,9,14,15,16,17,18,19,20,21,22,23,24]$

\section{Postoperative pain management:}

Generally paracetamol is considered a safe over-thecounter analgesic for patients taking antiplatelet medications and it may be taken in normal doses if pain control is needed and no contraindication exists.

NSAIDs should be used with caution in combination with aspirin or clopidogrel. They can damage the lining of the gastro-intestinal tract leading to bleeding that may be worsened by aspirin or clopidogrel. [6]

\section{Conclusions:}

Long-standing dogma concerning the exaggerated risk for bleeding during and after dental procedures results in stopping antiplatelet medications before a procedure or in unnecessary deferral of dental care.

This practice persists despite published recommendations to the contrary. 
Most studies and guidelines advise to not routinely discontinue antiplatelet medication before dental surgery because bleeding complications following dental procedures, while inconvenient, do not carry the same risks as thromboembolic complications.

According to the 2008 American College of Chest Physicians (ACCP) and American Dental Association Guidelines, aspirin may be discontinued preoperatively in patients who use it in primary prevention and are not at a high risk of cardiac events.
Patients with liver impairment, and/or alcoholism, renal failure, thrombocytopenia, haemophilia or other disorder of haemostasis, currently receiving a course of cytotoxic medication, marrow disorders, any concurrent medication affecting haemostasis such as anticoagulants or anti-inflammatory drugs, may be at higher risk of prolonged bleeding following dental procedures should be consulted with medical specialist (cardiologist). Referral to a dental hospital or hospital based dental clinic may be appropriate.

\section{REFERENCES:}

1. Brennan MT, Wynn RL, Miller CS. Aspirin and bleeding in dentistry: an update and recommendations. Oral surgery, Oral Surg Oral Med Oral Pathol Oral Radiol Endod. 2007 Sep;104(3):316-23. Epub 2007 Jul 6. [PubMed] [CrossRef]

2. Harrison P, Frelinger AL 3rd, Furman MI, Michelson AD. Measuring antiplatelet drug effects in the laboratory. Thromb Res. 2007; 120(3):323-336, Epub 2007 Jan 17. [PubMed] [CrossRef]

3. Savi P, Nurden P, Nurden AT, Levy-Toledano S, Herbert JM. Clopidogrel: a review of its mechanism of action. Platelets. 1998; 9(3-4):251-5. [PubMed] [CrossRef]

4. Pototski M, Amenabar JM. Dental management of patients on anticoagulation or antiplatelet therapy. J Oral Sci. 2007 Dec;49(4):253-258. [PubMed] [CrossRef]

5. Sinha N. Ticagrelor: molecular discovery to clinical evidence Ticagrelor: a novel antiplatelet agent. Indian Heart J. 2012 Sep-Oct; 64(5):497-502. Epub 2012 Sep 7. [PubMed] [CrossRef]

6. Popiliev I. Clinical and therapeutic guide of Cardiology. Med. Pub House "Raikov" 2002; pp222232. [in Bulgarian]

7. Trendafilova D. Oral antithrombotic agents. From clinical trials to clinical practice. MedInfo. 2012, 12(9):p5-8 [in Bulgarian]

8. Belcheva A, Uzunov P. Pharmacology. Pub "Znanie". 2003; pp293-297 [in Bulgarian]
9. Lockhart PB, Gibson J, Pond SH, Leitch J. Dental management considerations for the patient with an acquired coagulopathy. Part 2: Coagulopathies from drugs. Br Dent $J$. 2003 Nov 8;195(9):405-501. [PubMed] [CrossRef]

10. Broomhead RH, Mallett SV. Clinical aspects of coagulation. Anaesthesia \& Intensive Care Medicine. 2010 May;11(5):195-199. [CrossRef]

11. Vaclavik J, Taborsky M. Antiplatelet therapy in the perioperative period. Eur J Inter Med. 2011 Feb;22(1):26-31. [PubMed] [CrossRef]

12. Ferrari E, Benhamou M, Cerboni P, Marcel B. Coronary Syndromes Following Aspirin Withdrawal A Special Risk for Late Stent Thrombosis. J Am Coll Cardiol. 2005 Feb 1;45(3):456-9. [PubMed] [CrossRef]

13. Gershlick AH, Richardson G. Drug eluting stents. BMJ. 2006 Dec 16;333(7581):1233-1234. [PubMed] [CrossRef]

14. Napenas JJ, Oost FC, Degroot A, Loven B, Hong CH, Brennan MT, et all. Review of postoperative bleeding risk in dental patients on antiplatelet therapy. Oral Surg Oral Med Oral Pathol Oral Radiol. 2013 Apr; 115(4): 491-9. Epub 2013 Jan 16. [PubMed] [CrossRef]

15. van Diermen DE, Aartman IH, Baart JA, Hoogstraten J, van der Waal I. Dental management of patients using antithrombotic drugs: critical appraisal of existing guidelines. Oral Surg Oral Med Oral Pathol Oral Radiol Endod. 2009 May;107(5):61624. [PubMed] [CrossRef]

16. Krishnan B, Shenoy NA, Alexander M. Exodontia and antiplatelet therapy. J Oral Maxillofac Surg. 2008 Oct;66(10):2063-6. [PubMed] [CrossRef]

17. Madan GA, Madan SG, Madan G, Madan AD. Minor oral surgery without stopping daily low-dose aspirin therapy: a study of 51 patients. $J$ Oral Maxillofac Surg. 2005 Sep;63(9):12625. [PubMed] [CrossRef]

18. Morimoto $\mathrm{Y}$, Niwa $\mathrm{H}$, Minematsu K. Hemostatic management of tooth extractions in patients on oral antithrombotic therapy. J Oral Maxillofac Surg. 2008 Jan;66(1):51-7. [PubMed] [CrossRef]

19. Park MW, Her SH, Kwon JB, Lee JB, Choi MS, Cho JS, et al. Safety of dental extractions in coronary drugeluting stenting patients without stopping multiple antiplatelet agents. Clin Cardiol. 2012 Apr;35(4):225-230. Epub 2012 Jan 25. [PubMed] [CrossRef]

20. Cardona-Tortajada F, SainzGomez E, Figuerido-Garmendia J, Liron de Robles-Adsuar A, MorteCasabo A, Giner-Munoz F, et al. Dental extractions in patients on antiplatelet therapy. A study conducted by the Oral Health Department of the Navarre Health Service. Med Oral Patol Oral Cir Bucal. 2009 Nov 1;14 (11):e588592. [CrossRef]

21. Valerin MA, Brennan MT, Noll 
JL, Napecas JJ, Kent ML, Fox PC, et al. Relationship between aspirin use and postoperative bleeding from dental extractions in a healthy population. Oral Surg Oral Med Oral Pathol Oral Radiol. 2006 Sep;102(3):326. [CrossRef]

22. Atanasov D. (editor). Oral Surgery. Plovdiv: B.i., 2011; p925 (pp232-233). [in Bulgarian]

23. Nooh N. The effect of aspirin on bleeding after extraction of teeth. Saudi Dental Journal. (2009) 21(2): 57-61.

24. Lillis T, Ziakas A, Koskinas K, Tsirlis A, Giannoglou G. Safety of
Dental Extractions During Uninterrupted Single or Dual Antiplatelet Treatment. Am J Cardiol. 2011 Oct 1;108(7):964-967. [PubMed] [CrossRef]

25. Lozano AC, Sarriyn Perez MG, Gavaldб Esteve C. Dental management in patients with hemostasis alteration. J Clin Exp Dent. 2011 Apr;3(2):e1206. [CrossRef] 26. Carter G, Goss A, Lloyd J, Tocchetti R. Tranexamic Acid Mouthwash Versus Autologous Fibrin Glue in Patients Taking Warfarin Undergoing Dental Extractions: A
Randomized Prospective Clinical Study. J Oral Maxillofac Surg. 2003 Dec;61(12):1432-5. [PubMed] [CrossRef]

27. Bodner L, Weinstein J.M., Baumgarten A.K. Efficacy of fibrin sealant in patients on various levels of oral anticoagulant undergoing oral surgery. Oral Surg Oral Med Oral Pathol Oral Radiol Endod. 1998 Oct;86(4):421-4. [PubMed]

28. Mankad PS, Codispoti M. The role of fibrin sealants in hemostasis. Am J Surg. 2001 Aug;182(2 Suppl): 21S-28S. [PubMed].

\section{Correspondence address:}

Atanaska Dinkova, DMD, DDS

Department of Oral surgery, Faculty of Dental Medicine, Medical University Plovdiv, Bulgaria.

E-mail: dinkova_asia@yahoo.com; 